\title{
Risco de queda em idosos residentes em instituições de longa permanência
}

\author{
Risk of falling among elderly people living in long-term care facilities \\ Riesgo de caídas entre las personas mayores que viven en centros de atención a largo plazo
}

Recebido: 24/03/2021 | Revisado: 30/03/2021 | Aceito: 30/03/2021 | Publicado: 10/04/2021

\author{
Pedro Venicius de Sousa Batista \\ ORCID: https://orcid.org/0000-0002-9441-0996 \\ Centro Universitário UNINOVAFAPI, Brasil \\ E-mail: pedroveni@outlook.com \\ Nyara Caroline dos Santos \\ ORCID: https://orcid.org/0000-0001-6342-6912 \\ Centro Universitário UNINOVAFAPI, Brasil \\ E-mail: caroline.ncv@hotmail.com.br \\ Yan Ezequiel Sousa Oliveira \\ ORCID: https://orcid.org/0000-0003-4469-8327 \\ Centro Universitário UNINOVAFAPI, Brasil \\ E-mail: yanezequiel@hotmail.com \\ Ana Maria Ribeiro dos Santos \\ ORCID: https://orcid.org/0000-0002-5825-5335 \\ Universidade Federal do Piauí, Brasil \\ E-mail: ana.mrsantos@gmail.com \\ Ivonizete Pires Ribeiro \\ ORCID: https://orcid.org/0000-0003-0737-5430 \\ Centro Universitário UNINOVAFAPI, Brasil \\ E-mail: ivonizete.ribeiro@uninovafapi.edu.br \\ Francisca Cecília Viana Rocha \\ ORCID: https://orcid.org/0000-0002-0837-6032 \\ Centro Universitário UNINOVAFAPI, Brasil \\ E-mail: fceciliavr@hotmail.com
}

\begin{abstract}
Resumo
Objetivos: caracterizar as produções científicas levantadas considerando as variáveis: autores, tipo de estudo, base de dados, país, periódico e ano de publicação; descrever os fatores associados ao risco de quedas em idosos residentes em Instituição de Longa Permanência; discutir os mecanismos de prevenção desse evento nos idosos residentes nessas instituições e identificar a prevalência de quedas entre os idosos residentes em ILPIs. Metodologia: estudo do tipo revisão integrativa de literatura que incluiu artigos publicados no período de janeiro de 2010 a outubro de 2020 . A busca na literatura foi realizada nas seguintes bases de dados: LILACS, MEDLINE, BDENF, SciELO e CINAHL. Na amostra final foram selecionados 21 artigos. Resultados: os estudos incluídos foram escritos na língua portuguesa e inglesa. Quanto à origem dos estudos, dezesseis artigos foram desenvolvidos no Brasil, dois na China, um no Japão, um na Espanha e um no Canadá. De acordo com os dados levantados a partir dos artigos selecionados, os resultados foram discutidos em duas categorias: fatores associados ao risco de quedas em idosos residentes em Instituição de Longa Permanência e as medidas para prevenção desse risco serão apresentados em duas categorias. Conclusão: tratase de temática ainda recente, porém com significativa prevalência em idosos institucionalizados, o que requer urgente adoção de medidas preventivas. A articulação multiprofissional e intersetorial pode favorecer o engajamento de toda sociedade em busca de soluções efetivas para a redução do número de quedas em decorrência do processo de envelhecimento entre os idosos institucionalizados.
\end{abstract}

Palavras-chave: Idoso; Idoso de 80 anos ou mais; Acidentes por quedas; Instituição de longa permanência para Idosos.

\begin{abstract}
Objectives: characterize the scientific productions raised considering the variables: authors, type of study, database, parents, journal and year of publication; describe the factors associated with risk of falls among elderly people residing in a Long Term Care Facility; discuss the mechanisms for preventing this event in the elderly living in these institutions and identifying the prevalence of falls among elderly people living in LTCIs. Methodology: review type study integrative literature which included articles published from January 2010 to October 2020. The literature search was carried out in the following databases: LILACS, MEDLINE, BDENF, SciELO and CINAHL. At final sample, 21 articles were selected. Results: the included studies were written in the Portuguese and English. As for the origin of the studies, sixteen articles were developed in Brazil, two in China, one in Japan, one in Spain and one in Canada. In According to the data collected from the selected articles, the results were discussed in two categories:
\end{abstract}


factors associated with the risk of falls in elderly residents of an institution Long-Term Care and measures to prevent this risk will be presented in two categories. Conclusion: this is a recent topic, but with significant prevalence in institutionalized elderly, which requires urgent adoption of preventive measures. The articulation multidisciplinary and intersectoral approach can favor the engagement of the whole society in search of effective solutions for reducing the number of falls as a result of the aging among institutionalized elderly.

Keywords: Aged; Aged 80 years or older; Accidental falls; Homes for the aged.

\section{Resumen}

Objetivos: caracterizar las producciones científicas planteadas considerando las variables: autores, tipo de estudio, base de datos, país, revista y año de publicación; describir los factores asociados con el riesgo de caídas en los ancianos que viven en un Centro de Atención a Largo Plazo; discutir los mecanismos de prevención de este evento en los ancianos residentes en estas instituciones e identificar la prevalencia de caídas entre ancianos residentes en LTCF. Metodología: estudio integrador de revisión de la literatura que incluyó artículos publicados desde enero de 2010 a octubre de 2020. La búsqueda de literatura se realizó en las siguientes bases de datos: LILACS, MEDLINE, BDENF, SciELO y CINAHL. En la muestra final se seleccionaron 21 artículos. Resultados: los estudios incluidos se redactaron en portugués e inglés. En cuanto al origen de los estudios, se desarrollaron dieciséis artículos en Brasil, dos en China, uno en Japón, uno en España y uno en Canadá. Según los datos recolectados de los artículos seleccionados, los resultados se discutieron en dos categorías: factores asociados al riesgo de caídas en personas mayores que residen en una Institución de Cuidados de Larga Duración y las medidas para prevenir este riesgo se presentarán en dos categorías. Conclusión: este es un tema reciente, pero con una prevalencia significativa en ancianos institucionalizados, que requiere la adopción urgente de medidas preventivas. La articulación multiprofesional e intersectorial puede favorecer el compromiso de toda la sociedad en la búsqueda de soluciones efectivas para la reducción del número de caídas por proceso de envejecimiento entre los ancianos institucionalizados.

Palabras clave: Anciano; Ancianos de 80 años o más; Accidentes por caídas; Centro de atención a largo plazo para ancianos.

\section{Introdução}

O envelhecimento é um processo irreversível em crescimento nas sociedades, que se encontra em destaque desde as últimas décadas do século passado. O aumento significativo do número de idosos se deve ao declínio rápido e acentuado da fecundidade e a queda da mortalidade. Com isso, a longevidade da população eleva-se, sendo que as pessoas idosas podem apresentar doenças crônicas que aumentam sua vulnerabilidade e ampliam as possibilidades de maior incapacidade funcional (Silva et al., 2014).

Constata-se que em 1980 a população mundial com 60 anos ou mais correspondia a 382 milhões de pessoas sendo que no ano de 2017 representava 962 milhões. Estima-se que esse número dobrará novamente em 2050, quando atingirá cerca de 2,1 bilhões de pessoas idosas no mundo. Projeções indicam que nesse último ano citado, haverá mais pessoas maiores de 60 anos do que adolescentes e jovens em idade entre 10 a 24 anos. Destaca-se ainda que em relação ao idoso de 80 anos ou mais, projeta-se um aumento global de 137 para 425 milhões de pessoas entre os anos de 2017 e 2050. Isso se dará pela redução da taxa de natalidade e fecundidade e pelo crescimento populacional, sendo esse fato mais prevalente em países em desenvolvimento (United Nations, 2017).

No Brasil, pesquisa realizada em julho de 2018, evidenciou que a população brasileira estará em trajetória de envelhecimento até 2060, estimando-se que nesse referido ano o percentual da população com 65 anos ou mais de idade chegará a 25,5\% (58,2 milhões), enquanto em 2018 essa proporção era de 9,2\% (19,2 milhões). Já os jovens (0 a 14 anos) deverão representar 14,7\% da população (33,6 milhões) em 2060, frente a 21,9\% (44,5 milhões) existente em 2018 (Ibge, 2018).

Considerando o aumento da proporção de idosos, sua longevidade, as dificuldades culturais e socioeconômicas relacionadas à pessoa idosa e seus cuidadores, as Instituições de Longa Permanência para Idosos (ILPI) tornaram-se alternativas importantes de acolhimento de pessoas idosas, principalmente nos países em desenvolvimento, nos quais questões referentes ao tema ainda são tratadas de forma pouco resolutiva (Fagundes et al., 2017). 
As ILPIs são consideradas instituições governamentais ou não governamentais, de caráter residencial, que se destinam ao domicílio coletivo de pessoas idosas com ou sem suporte familiar, em condição de liberdade, dignidade e cidadania. Em síntese, a ILPI é uma residência coletiva que atende a idosos independentes em situação de carência familiar e/ou de renda, bem como aqueles com dificuldades para o exercício das atividades diárias, que precisam de cuidados prolongados (Linder $e t$ al., 2020).

Visando facilitar e padronizar a fiscalização das ILPIs no território nacional, foi aprovada a Resolução da Diretoria Colegiada (RDC) $n^{\circ} 283$, que regulamenta e define normas de funcionamento para as ILPIs de caráter residencial e determina que as secretarias de saúde - estadual, municipal e do Distrito Federal - devem implantar procedimentos para adoção do regulamento técnico, podendo adotar normas de caráter suplementar, com a finalidade de adequá-las às especificidades locais (Carvalho, 2014).

Destaca-se que a institucionalização tem influência no risco de quedas em idosos, uma vez que a mudança do ambiente familiar para a ILPI, pela possibilidade de isolamento social e menor atividade, pode acontecer alterações psicológicas, cognitivas e funcionais. Ademais, ressalta-se que a institucionalização amplia, na população idosa, um perfil clínico funcional e psicocognitivo mais ligado aos fatores de risco de quedas, como maior dependência, estado depressivo, redução da capacidade funcional e medo de cair (Freitas et al., 2017). Neste estudo, adotou-se o conceito de queda como o deslocamento não intencional do corpo para um nível inferior à posição inicial com incapacidade de correção em tempo hábil e apoio no solo, com ou sem perda de consciência ou ocorrência de lesões, determinado por naturezas multifatoriais que comprometem a estabilidade (Oms, 2010).

Mundialmente, dentre os fatores etiológicos determinantes de morte, destacam-se as causas externas (CE), as quais rotulam as quedas como agente precípuo de morte acidental em idosos. Nesse sentido, as CE são designadas como agravos à saúde representados por traumas, lesões, violência, envenenamento, acidentes de transportes, agressões, afogamentos e quedas. Em 2012 as quedas alcançaram o $21^{\circ}$ lugar em causa de mortes e o $11^{\circ}$ na faixa etária a partir de 70 anos. Em relação ao número de mortes em decorrência das quedas, estima-se um avanço em 2030, quando essa causa passará a representar o $17^{\circ}$ lugar no contexto global (Corassa et al., 2017).

Nesse contexto, observa-se que idosos que residem em comunidade representam aproximadamente um terço da população idosa que sofre múltiplas quedas a cada ano. Já aqueles que residem em ILPI a incidência é mais alta e apresentam três vezes mais chances de cair dos que aqueles que residem em comunidades, sendo que 39,8\% apresentam idade entre 80 a 89 anos. Os dados justificam-se devido os idosos institucionalizados possuírem características típicas, como hábitos sedentários, diminuição da autonomia e abandono familiar, fatores esses que contribuem para o aumento de prevalências relacionadas às morbidades e comorbidades, em especial as quedas (Gomes et al., 2014).

Dessa forma, deve-se contribuir para identificar o risco de tais ocorrências a fim de possibilitar uma vida mais saudável a esse grupo populacional e propiciar estratégias de prevenção e promoção de saúde. Ao considerar todo o contexto citado, o objeto de estudo desta pesquisa foram os fatores associados ao risco de quedas em idosos residentes em Instituição de Longa Permanência. Os objetivos deste estudo são: caracterizar as produções científicas levantadas considerando as variáveis: autores, tipo de estudo, base de dados, país, periódico e ano de publicação; descrever os fatores associados ao risco de quedas em idosos residentes em Instituição de Longa Permanência; discutir os mecanismos de prevenção desse evento nos idosos residentes nessas instituições; identificar a prevalência de quedas entre os idosos residentes em ILPIs. 


\section{Metodologia}

Trata-se de um estudo do tipo revisão integrativa de literatura, definida como método de pesquisa de dados secundários, em que os estudos relacionados a um determinado assunto são sumarizados permitindo assim a conclusão geral de inúmeros estudos por meio do processo de análise sistemática e síntese da literatura de pesquisa (Galvão et al., 2010).

Para elaboração desta pesquisa, seguiu-se as etapas definidas por Galvão et al. (2010), quais sejam: elaboração da questão da pesquisa, busca ou amostragem na literatura dos estudos primários, extração dos dados dos estudos primários, avaliação dos estudos primários incluídos, análise e síntese do resultado da revisão e apresentação da revisão integrativa.

O estudo teve como questão: "Quais os fatores associados ao risco de quedas em idosos residentes em Instituição de Longa Permanência?”, elaborada por meio da estratégia PICo, em que P: corresponde aos participantes, no caso os idosos, I: fenômeno de interesse, representado pela ocorrência do evento acidentes por queda e Co: contexto do estudo, que são as Instituições de Longa Permanência (Karino \& Felli, 2012).

A busca na literatura foi realizada em outubro de 2020, nas seguintes bases de dados: Literatura Latino-americana e do Caribe em Ciências da Saúde (LILACS), Medical Literature Analysis and Retrieval System Online (MEDLINE), Base de Dados em Enfermagem (BDENF), na Biblioteca Virtual Scientific Electronic Library Online (SciELO) e na CINAHL (Cumulative Index of Nursing and Allied Health Literature). As buscas foram realizadas utilizando os Descritores em Ciências da Saúde (DeCS) da Biblioteca Regional de Medicina (Bireme) e seus equivalentes no idioma inglês no Medical Subject Headings (MeSH): idoso (aged), acidentes por quedas (acidental falls), instituição de longa permanência para idosos (homes for the aged), assim como descritores não controlados: quedas (falls), com auxílio dos operadores booleano "AND" e "OR". Ressalta-se que a busca foi realizada de forma independente por três pesquisadores, conforme recomendam Galvão et al. (2010).

Adotou-se como critérios de inclusão: artigo original, com texto completo, publicados em português, inglês e espanhol, indexados nas bases de dados consultadas referente ao período de janeiro de 2010 à outubro de 2020 que apresentassem fatores associados ao risco de quedas em idosos residentes em Instituição de Longa Permanência e mecanismos de prevenção desses eventos nessa população. Em contrapartida foram excluídos artigos de revisão, teses, dissertações e aqueles que não atenderem ao objeto do estudo. Os artigos duplicados foram considerados apenas uma vez.

$\mathrm{Na}$ busca ou amostragem na literatura, levantaram-se 403 publicações, tendo em vista que os estudos duplicados foram contados apenas uma vez, excluíram-se inicialmente 25 artigos.

Na sequência realizou-se a leitura de títulos e resumos dos 378 artigos quando se considerou potencialmente elegível para leitura na íntegra aquelas publicações que identificaram o risco de quedas em idosos residentes em ILPIs, quando então elegeu-se 59 investigações para participarem desta etapa. Após aplicação dos critérios de inclusão e exclusão, se excluiu 38 estudos, por não atenderem ao objeto de estudo ou por se tratar de revisão da literatura, selecionando-se então, para a amostra final desta revisão, 21 artigos. Não foram incluídos outros estudos após o processo de busca manual.

Destaca-se que para seleção das publicações, seguiram-se as recomendações do Preferred Reporting Items for Systematic Reviews and Meta-Analyses - PRISMA (Moher et al., 2009), conforme apresentado na Figura 1, a seguir. 
Figura 1 - Fluxograma de seleção dos estudos primários, elaborado a partir da recomendação PRISMA*. Teresina, PI, Brasil, 2020 .

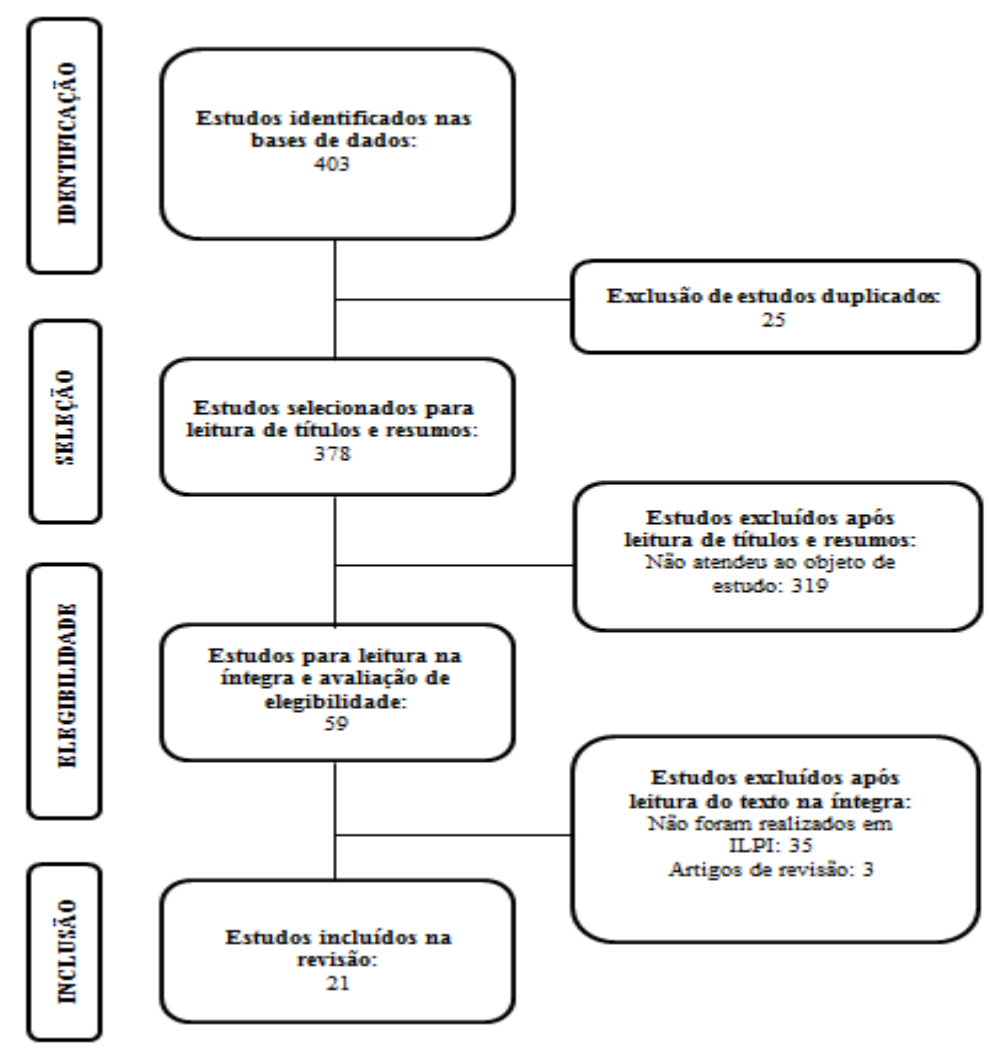

Fonte: Autores (2020).

Para a extração e síntese das informações dos estudos selecionados, foi utilizado um formulário elaborado pelos pesquisadores, adaptado do formulário da Red de Enfermería en Salud Ocupacional (RedENSO Internacional) (Marziale, 2015). Foram extraídas às seguintes informações: título do artigo, base de dados, país, periódico e ano de publicação, tipo de estudo, autores, prevalência de quedas, fatores associados ao risco de quedas e mecanismos de prevenção de quedas.

$\mathrm{Na}$ quarta etapa, os dados coletados foram agrupados para a identificação do assunto principal em cada estudo pesquisado. Após isso, foram analisados por categoria temática. Como última etapa, apresenta-se este relatório final que mostra uma síntese detalhada da organização da revisão e seus efeitos (Galvão et al., 2010).

Como a pesquisa não envolve seres humanos ela não foi submetida ao Comitê de Ética em Pesquisa. No entanto, o presente estudo foi enviado e cadastrado na Coordenação de Pesquisa, Extensão e Pós-Graduação, sob o processo no $122 / 2020$ do Centro Universitário - UNINOVAFAPI, para registro e conhecimento.

\section{Resultados}

Nesta revisão foram selecionados 21 artigos, dos quais oito $(38,1 \%)$ foram identificados na LILACS, seis $(28,6 \%)$ na MEDLINE, quatro (19\%) na BDENF-Enfermagem e três (14,3\%) na SciELO, conforme apresentado no Quadro 1, adiante.

Os estudos incluídos foram escritos na língua portuguesa e inglesa. Quanto à origem dos estudos, dezesseis artigos $(76,1 \%)$ foram desenvolvidos no Brasil, dois $(9,5 \%)$ na China, um $(4,8 \%)$ no Japão, um $(4,8 \%)$ na Espanha e um $(4,8 \%)$ no Canadá. No que diz respeito aos anos de publicação, foram publicados durantes os anos de 2010 (n= 3/14,3\%), 2012 $(n=2 / 9,5 \%), 2013(n=2 / 9,5 \%), 2014(n=3 / 14,3 \%), 2015(n=3 / 14,3 \%), 2016 \quad(n=1 / 4,8 \%), 2017(n=2 / 9,5 \%), 2019(n=4 / 19 \%)$, 2020( $n=1 / 4,8 \%)$. No que tange aos desenhos dos estudos, dez (47,6\%) eram de método transversal, seis $(28,5 \%)$ longitudinal, 
três $(14,3 \%)$ de coorte, um $(4,8 \%)$ qualitativo e um $(4,8 \%)$ ensaio clínico randomizado. Desses, oito $(38,1 \%)$ foram publicados em periódicos de Enfermagem e treze (61,9\%) em revistas interdisciplinares de saúde.

Quadro 1 - Síntese dos estudos incluídos na revisão, segundo base de dados, país, ano de publicação, título, autores, desenho do estudo e periódico. Teresina, PI, 2020.

\begin{tabular}{|c|c|c|c|}
\hline $\begin{array}{l}\text { Base/País/ } \\
\text { Ano }\end{array}$ & Título & Autores/Desenho & Periódico (v/n) \\
\hline $\begin{array}{c}\text { BDENF } \\
\text { Brasil } \\
2010 \\
\end{array}$ & $\begin{array}{l}\text { Prevalência e caraterísticas das quedas de } \\
\text { idosos institucionalizados }\end{array}$ & $\begin{array}{c}\text { Ferreira, D.C. O. e } \\
\text { Yoshitome, A.Y. } \\
\text { Transversal Retrospectivo } \\
\end{array}$ & $\begin{array}{l}\text { Rev. bras. } \\
\text { Enferm. } \\
\text { (v. 63/n.6) }\end{array}$ \\
\hline $\begin{array}{c}\text { SciELO } \\
\text { Brasil } \\
2010 \\
\end{array}$ & $\begin{array}{l}\text { Ocorrência de quedas em idosos residentes } \\
\text { em instituições de longa permanência em } \\
\text { Pelotas, Rio Grande do Sul, Brasil }\end{array}$ & $\begin{array}{l}\text { Álvares, L.M. et al. } \\
\text { Transversal }\end{array}$ & $\begin{array}{l}\text { Cad. Saúde } \\
\text { Pública } \\
(\mathrm{v} .26 / \mathrm{n} .1) \\
\end{array}$ \\
\hline $\begin{array}{l}\text { MEDLINE } \\
\text { Japão } \\
2010\end{array}$ & $\begin{array}{l}\text { Urinary incontinence and behavioral } \\
\text { symptoms are independent risk factors for } \\
\text { recurrent and injurious falls, respectively, } \\
\text { among residents in long-term care } \\
\text { facilities }\end{array}$ & $\begin{array}{c}\text { Hasegawa, J. et al. } \\
\text { Longitudinal Prospectivo }\end{array}$ & $\begin{array}{l}\text { Arch. Gerontol. } \\
\text { Geriatr. } \\
\text { (v.50/n.1) }\end{array}$ \\
\hline $\begin{array}{c}\text { SciELO } \\
\text { Brasil/ } \\
2012 \\
\end{array}$ & $\begin{array}{l}\text { Condições visuais autorrelatadas e quedas } \\
\text { em idosos institucionalizados }\end{array}$ & $\begin{array}{l}\text { Menezes, R.L e Bachion, } \\
\text { M.M. Longitudinal } \\
\text { Prospectivo } \\
\end{array}$ & $\begin{array}{l}\text { Rev Bras } \\
\text { Oftalmol. } \\
\text { (v.71/n.1) }\end{array}$ \\
\hline $\begin{array}{c}\text { LILACS } \\
\text { Brasil } \\
2012 \\
\end{array}$ & $\begin{array}{l}\text { Ocorrência de quedas e seu contexto num } \\
\text { seguimento de dois anos em idosos } \\
\text { institucionalizados }\end{array}$ & $\begin{array}{l}\text { Menezes, R.L. e Bachion, } \\
\text { M.M. } \\
\text { Longitudinal Prospectivo } \\
\end{array}$ & $\begin{array}{l}\text { Rev. Eletr. Enf. } \\
\text { (v.14/n.3) }\end{array}$ \\
\hline $\begin{array}{l}\text { LILACS } \\
\text { Brasil } \\
2013 \\
\end{array}$ & $\begin{array}{l}\text { Quedas e fraturas entre residentes de } \\
\text { instituições de longa permanência para } \\
\text { idosos }\end{array}$ & $\begin{array}{l}\text { Del Duca et al. } \\
\text { Transversal }\end{array}$ & $\begin{array}{l}\text { Rev. bras. } \\
\text { epidemiol. } \\
\text { (v.16/n.1) }\end{array}$ \\
\hline $\begin{array}{l}\text { LILACS } \\
\text { Brasil } \\
2013 \\
\end{array}$ & $\begin{array}{l}\text { Risco de queda em idosos com doença de } \\
\text { Alzheimer institucionalizados }\end{array}$ & $\begin{array}{l}\text { Ferreira, L.L. et al. } \\
\quad \text { Transversal }\end{array}$ & $\begin{array}{l}\text { ConScientiae } \\
\text { Saúde } \\
\text { (v.12/n.3) }\end{array}$ \\
\hline $\begin{array}{c}\text { LILACS } \\
\text { Brasil } \\
2014 \\
\end{array}$ & $\begin{array}{l}\text { Ações institucionais alicerçadas } \\
\text { diagnósticos de enfermagem } \\
\text { prevenção de quedas em idosos }\end{array}$ & $\begin{array}{c}\text { Valcarenghi, R.V. } \\
\text { et al. } \\
\text { Qualitativo } \\
\end{array}$ & $\begin{array}{l}\text { Rev.Rene. } \\
\text { (v.15/n.2) }\end{array}$ \\
\hline $\begin{array}{l}\text { LILACS } \\
\text { Brasil } \\
2014\end{array}$ & $\begin{array}{l}\text { Influência do tempo de institucionalização } \\
\text { no equilíbrio postural e no risco de quedas } \\
\text { de idosos: estudo transversal }\end{array}$ & $\begin{array}{l}\text { Batista, W.O. et al. } \\
\text { Transversal }\end{array}$ & $\begin{array}{l}\text { Rev.Latino- } \\
\text { Am. } \\
\text { Enfermagem } \\
(\mathrm{v} .22 / \mathrm{n} .4)\end{array}$ \\
\hline $\begin{array}{c}\text { BDENF } \\
\text { Brasil } \\
2014 \\
\end{array}$ & $\begin{array}{l}\text { Monitoramento de episódios de quedas em } \\
\text { Instituição para Idosos }\end{array}$ & $\begin{array}{c}\text { Baixinho, C.R.S.L e Dixe, } \\
\text { M.A.C.R } \\
\text { Transversal } \\
\end{array}$ & $\begin{array}{l}\text { Rev. eletrônica } \\
\text { enferm } \\
\text { (v.16/n.1) } \\
\end{array}$ \\
\hline $\begin{array}{l}\text { LILACS } \\
\text { Brasil } \\
2015\end{array}$ & $\begin{array}{l}\text { Coorte de idosos institucionalizados: } \\
\text { fatores de risco para queda a partir do } \\
\text { diagnóstico de enfermagem }\end{array}$ & $\begin{array}{l}\text { Reis, K.M.C e Jesus, C.A.C. } \\
\text { Coorte prospectivo. }\end{array}$ & $\begin{array}{l}\text { Rev.Latino- } \\
\text { Am. } \\
\text { Enfermagem } \\
\text { (v.23/n.5) }\end{array}$ \\
\hline $\begin{array}{l}\text { MEDLINE } \\
\text { Canadá } 2015\end{array}$ & $\begin{array}{l}\text { Use of fall risk increasing drugs in } \\
\text { residents of retirement villages: A pilot } \\
\text { study of long term care and retirement } \\
\text { home residents in Ontario, Canada }\end{array}$ & $\begin{array}{l}\text { Rojas-Fernandez, C.R. et al } \\
\text { Transversal Retrospectivo }\end{array}$ & $\begin{array}{c}\text { BMC Res } \\
\text { Notes (v.8/n.1) }\end{array}$ \\
\hline $\begin{array}{c}\text { BDENF } \\
\text { Brasil } \\
2015 \\
\end{array}$ & $\begin{array}{l}\text { Quedas em Instituições para idosos: } \\
\text { caracterização dos episódios de quedas e } \\
\text { fatores de risco associados }\end{array}$ & $\begin{array}{l}\text { Baixinho, C.R.S.L e Dixe, } \\
\text { M.A.C.R. } \\
\text { Longitudinal prospectivo }\end{array}$ & $\begin{array}{c}\text { Rev. eletrônica } \\
\text { enferm } \\
\text { (v.17/n.4) }\end{array}$ \\
\hline $\begin{array}{l}\text { MEDLINE } \\
\text { Espanha } \\
2016\end{array}$ & $\begin{array}{l}\text { Influence of cognitive impairment on fall } \\
\text { risk among elderly nursing home residents }\end{array}$ & $\begin{array}{l}\text { Seijo-Martinez, M.S. et al } \\
\text { Longitudinal }\end{array}$ & $\begin{array}{l}\text { Int } \\
\text { Psychogeriatr } \\
\text { (v.28/n.12) }\end{array}$ \\
\hline $\begin{array}{c}\text { BDENF } \\
\text { Brasil } \\
2017 \\
\end{array}$ & $\begin{array}{l}\text { Quedas em idosos institucionalizados: } \\
\text { riscos, consequências e antecedentes }\end{array}$ & $\begin{array}{l}\text { Araújo Neto, A.H. et al. } \\
\text { Transversal }\end{array}$ & $\begin{array}{l}\text { Rev.Bras } \\
\text { Enferm } \\
\text { (v.70/n.4) } \\
\end{array}$ \\
\hline
\end{tabular}




\begin{tabular}{|c|c|c|c|}
\hline $\begin{array}{l}\text { LILACS } \\
\text { Brasil } \\
2017\end{array}$ & $\begin{array}{l}\text { Associação entre número de quedas e força } \\
\text { muscular de idosos residentes em } \\
\text { instituições de longa permanência }\end{array}$ & $\begin{array}{l}\text { Tomicki, C. et al. Ensaio } \\
\text { clínico randomizado }\end{array}$ & $\begin{array}{l}\text { Revista Kairós } \\
\text { (v.20/n.2) }\end{array}$ \\
\hline $\begin{array}{l}\text { LILACS } \\
\text { Brasil } \\
2019\end{array}$ & $\begin{array}{l}\text { Análise dos fatores de risco para queda em } \\
\text { idosos institucionalizados }\end{array}$ & $\begin{array}{l}\text { Rosa, V.P.P. et al. } \\
\text { Coorte Prospectivo }\end{array}$ & $\begin{array}{l}\text { Rev. bras. } \\
\text { geriatr. } \\
\text { Gerontol. } \\
\text { (v. 22/n.1) }\end{array}$ \\
\hline $\begin{array}{l}\text { MEDLINE } \\
\text { China } \\
2019\end{array}$ & $\begin{array}{l}\text { Insomnia, Benzodiazepine Use, and Falls } \\
\text { among Residents in Long-term Care } \\
\text { Facilities. }\end{array}$ & $\begin{array}{l}\text { Jiang, Y. et al. } \\
\text { Coorte Prospectiva }\end{array}$ & $\begin{array}{c}\text { Int. J. Environ. } \\
\text { Res. Public } \\
\text { Health } \\
\text { (v.16/n 23) }\end{array}$ \\
\hline $\begin{array}{l}\text { MEDLINE } \\
\text { China } \\
2019\end{array}$ & $\begin{array}{l}\text { Epidemiological characteristics and factors } \\
\text { influencing falls among elderly adults in } \\
\text { long-term care facilities in Xiamen, China. }\end{array}$ & Zhang, L. et al. Transversal & $\begin{array}{l}\text { Medicine } \\
\text { (v. } 98 / \mathrm{n} .8)\end{array}$ \\
\hline $\begin{array}{l}\text { MEDLINE } \\
\text { Brasil } \\
2019 \\
\end{array}$ & $\begin{array}{l}\text { Recurrent falls and risk factors among } \\
\text { institutionalized older people. }\end{array}$ & $\begin{array}{c}\text { Ferreira, L.M.B.M. } \\
\text { et al. } \\
\text { Longitudinal Concorrente }\end{array}$ & $\begin{array}{c}\text { Ciência \& } \\
\text { Saúde Coletiva, } \\
\text { (v.24/n.1) }\end{array}$ \\
\hline $\begin{array}{l}\text { SciELO } \\
\text { Brasil } \\
2020\end{array}$ & $\begin{array}{l}\text { Correlation between functional } \\
\text { independence and risk of falls in older } \\
\text { adults at three long-term care facilities }\end{array}$ & $\begin{array}{l}\text { Paula, J.G.F. et al. } \\
\text { Transversal }\end{array}$ & $\begin{array}{l}\text { Rev. Esc. } \\
\text { Enferm. USP. } \\
\text { (v. 54/ e3601) }\end{array}$ \\
\hline
\end{tabular}

Fonte: Autores (2020).

Para melhor visualização da apresentação dos artigos encontrados e para atender aos objetivos do estudo, elaborou-se o Quadro 2, o qual demonstra a prevalência de quedas, os fatores associados e os mecanismos de prevenção dos estudos selecionados.

Nesse contexto, observou-se que apenas dois $(9,5 \%)$ dos vinte artigos selecionados não apresentou a prevalência de queda em idosos institucionalizados, sendo que esta variou de $21,8 \%$ a $70 \%$. Em contrapartida, todos os artigos apresentaram fatores associados ao risco de quedas em ILPI. No que diz respeito aos mecanismos de prevenção $81 \%$ das investigações abordaram esse aspecto.

Quadro 2 - Objetivo, prevalência, fatores associados e mecanismos de prevenção nos artigos sobre queda em idosos em ILPIs. Teresina, PI, 2020.

\begin{tabular}{|c|c|c|c|}
\hline Título & Objetivos & $\begin{array}{c}\text { Prevalência } \\
\text { Fatores associados }\end{array}$ & Mecanismos de prevenção \\
\hline $\begin{array}{l}\text { Prevalência r e } \\
\text { caraterísticas das } \\
\text { quedas de idosos } \\
\text { institucionalizados }\end{array}$ & $\begin{array}{l}\text { Verificar a prevalência de quedas } \\
\text { em idosos residentes em uma } \\
\text { Instituição de Longa Permanência } \\
\text { localizada no município de São } \\
\text { Paulo; Caracterizar os idosos que } \\
\text { sofreram quedas no período } \\
\text { estudado, com relação a variáveis } \\
\text { demográficas e clínicas; Descrever } \\
\text { as características das quedas } \\
\text { ocorridas em relação a sua } \\
\text { frequência, causas, circunstâncias e } \\
\text { consequências. }\end{array}$ & 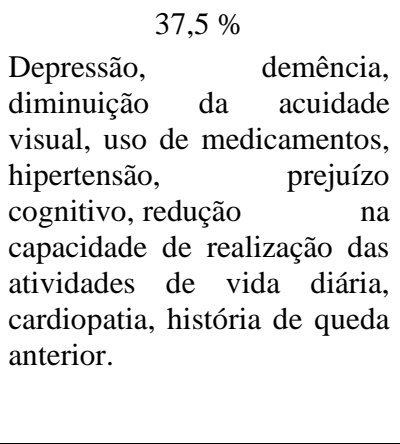 & $\begin{array}{l}\text { Reabilitação da força muscular, } \\
\text { equilíbrio e capacidade } \\
\text { funcional, redução da } \\
\text { polifarmácia, educação para o } \\
\text { autocuidado e aumento da } \\
\text { supervisão de enfermagem nos } \\
\text { períodos e locais de maior } \\
\text { incidência de quedas. }\end{array}$ \\
\hline $\begin{array}{l}\text { Ocorrência de quedas } \\
\text { em idosos residentes } \\
\text { em instituições de } \\
\text { longa permanência } \\
\text { em Pelotas, Rio } \\
\text { Grande do Sul, Brasil }\end{array}$ & $\begin{array}{l}\text { Descrever a ocorrência de quedas e } \\
\text { fatores associados entre idosos } \\
\text { residentes em instituições de longa } \\
\text { permanência na cidade de Pelotas, } \\
\text { Rio Grande do Sul, Brasil. }\end{array}$ & $\begin{array}{l}32,5 \% \\
\text { Escorregão, sentir tontura e } \\
\text { desequilíbrio, utilização de } \\
\text { psicotrópicos. }\end{array}$ & - \\
\hline $\begin{array}{lr}\text { Urinary incontinence } \\
\text { and } \\
\text { symptoms }\end{array}$ & $\begin{array}{l}\text { Examinar a associação entre vários } \\
\text { tipos de } \\
\text { urinária }\end{array}$ & $\begin{array}{r}24,4 \% \\
\text { Deficiência física moderada, }\end{array}$ & $\begin{array}{l}\text { Tratamento ou gestão } \\
\text { incontinência }\end{array} \quad \begin{array}{l}\text { darinária } \\
\mathrm{e}\end{array}$ \\
\hline
\end{tabular}




\begin{tabular}{|c|c|c|c|}
\hline $\begin{array}{l}\text { independent risk } \\
\text { factors for recurrent } \\
\text { and injurious falls, } \\
\text { respectively, among } \\
\text { residents in long-term } \\
\text { care facilities }\end{array}$ & $\begin{array}{l}\text { comportamentais entre os residentes } \\
\text { de instituições de longa } \\
\text { permanência usando os modelos de } \\
\text { riscos proporcionais de Cox. }\end{array}$ & $\begin{array}{l}\text { incontinência urinária } \mathrm{e} \\
\text { sintomas comportamentais. }\end{array}$ & sintomas comportamentais. \\
\hline $\begin{array}{lr}\text { Condições visuais } \\
\text { autorrelatadas } \\
\text { quedas em idosos } \\
\text { institucionalizados }\end{array}$ & $\begin{array}{lcc}\text { Avaliar as condições } & \text { visuais } \\
\text { autorrelatadas } & \text { por } & \text { idosos } \\
\text { institucionalizados e sua } & \text { relação } \\
\text { com acidentes por quedas. }\end{array}$ & $\begin{array}{l}54,2 \% \\
\text { Redução da acuidade visual, a } \\
\text { redução da sensibilidade de } \\
\text { contraste, déficit visual } \\
\text { autorrelatado e diminuição do } \\
\text { campo visual. }\end{array}$ & $\begin{array}{l}\text { O diagnóstico precoce de } \\
\text { comprometimentos visuais e/ou } \\
\text { a correção desses. }\end{array}$ \\
\hline $\begin{array}{l}\text { Ocorrência de quedas } \\
\text { e seu contexto num } \\
\text { seguimento de dois } \\
\text { anos em idosos } \\
\text { institucionalizados }\end{array}$ & 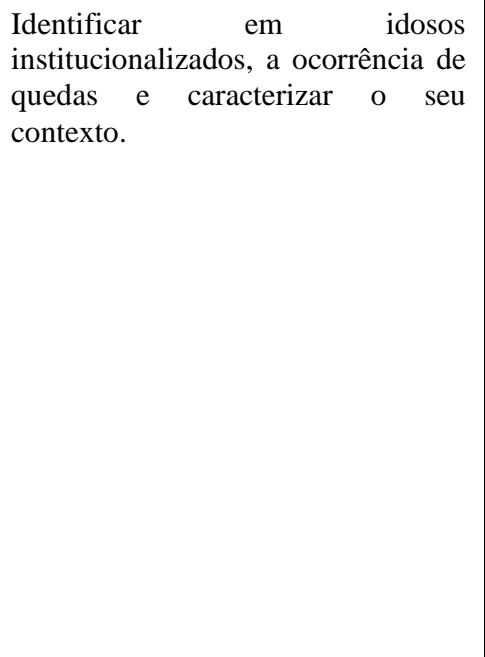 & $\begin{array}{l}54,2 \% \\
\text { O piso escorregadio, molhado } \\
\text { e irregular, obstáculos } \\
\text { ambientais, calçados com } \\
\text { chinelos. }\end{array}$ & $\begin{array}{l}\text { Programas de exercícios físicos, } \\
\text { instituir boletim de quedas com } \\
\text { data e hora e local da } \\
\text { ocorrência, atividade } \\
\text { desenvolvida, sintomas, tipos e } \\
\text { características de calçados } \\
\text { utilizados; reconhecer os idosos } \\
\text { que têm maior predisposição a } \\
\text { quedas, identificar os fatores } \\
\text { de risco extrínseco-ambientais e } \\
\text { os intrínsecos a que estão } \\
\text { expostos; uso de calçados } \\
\text { apropriados; instalar medidas } \\
\text { de segurança ambientais; } \\
\text { implementação de estratégias de } \\
\text { revitalização urbana, } \\
\text { especialmente nas calçadas e } \\
\text { meios-fios }\end{array}$ \\
\hline $\begin{array}{l}\text { Quedas e fraturas } \\
\text { entre residentes de } \\
\text { instituições de longa } \\
\text { permanência r para } \\
\text { idosos }\end{array}$ & $\begin{array}{l}\text { Investigar a ocorrência de quedas } \\
\text { e fraturas no último ano e fatores } \\
\text { associados } \\
\text { entre residentes de instituições de } \\
\text { longa } \\
\text { permanência para idosos (ILPI). }\end{array}$ & \begin{tabular}{ll}
\multicolumn{3}{c}{$38,9 \%$} \\
Idade, & incapacidade \\
funcional, & residir em \\
instituições & públicas \\
/filantrópicas & e ter sido \\
hospitalizado & nos últimos \\
anos. &
\end{tabular} & $\begin{array}{l}\text { Ajuste na altura da cama, uso de } \\
\text { meias antiderrapantes, } \\
\text { iluminação adequada, tapetes } \\
\text { fixos no solo e protetores de } \\
\text { quadril, ambientes físicos } \\
\text { adequados e profissionais } \\
\text { capacitados para o cuidado. }\end{array}$ \\
\hline $\begin{array}{l}\text { Risco de queda em } \\
\text { idosos com doença de } \\
\text { Alzheimer } \\
\text { institucionalizados }\end{array}$ & $\begin{array}{l}\text { Avaliar o impacto da doença de } \\
\text { Alzheimer no risco de queda em } \\
\text { idosos residentes em uma } \\
\text { instituição de longa permanência. }\end{array}$ & $\begin{array}{l}70 \% \\
\text { Doença de Alzheimer, tempo } \\
\text { de institucionalização, déficit } \\
\text { no equilíbrio, dificuldade na } \\
\text { marcha, perda de força } \\
\text { progressiva idade mais } \\
\text { avançada igual ou superior a } \\
80 \text { anos, sexo feminino. }\end{array}$ & - \\
\hline $\begin{array}{lr}\text { Ações institucionais } \\
\text { alicerçadas } & \text { em } \\
\text { diagnósticos } & \text { de } \\
\text { enfermagem } & \text { para } \\
\text { prevenção de } & \text { quedas } \\
\text { em idosos } & \end{array}$ & $\begin{array}{l}\text { Propor ações } \frac{2}{2} \text { institucionais } \\
\text { baseadas em diagnósticos de } \\
\text { enfermagem para a prevenção de } \\
\text { quedas em idosos. }\end{array}$ & $\begin{array}{l}43,3 \% \\
\text { Desníveis no chão, pisos sem } \\
\text { material antiderrapante, } \\
\text { ausência de sinalização, } \\
\text { tapetes soltos, móveis com } \\
\text { contorno pontiagudo, camas } \\
\text { sem grades de proteção e } \\
\text { iluminação inadequada, } \\
\text { roupas e sapatos de } \\
\text { numeração maiores, sem sola } \\
\text { adequada, apoio como } \\
\text { andadores e bengalas } \\
\text { impróprios para o uso, uso de } \\
\text { medicamentos. }\end{array}$ & 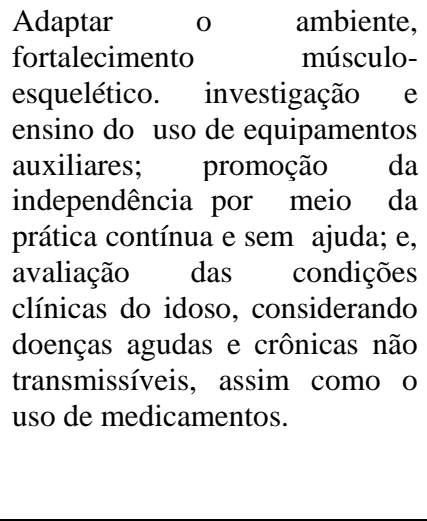 \\
\hline $\begin{array}{l}\text { Influência do tempo } \\
\text { de institucionalização } \\
\text { no equilíbrio postural } \\
\text { e no risco de quedas }\end{array}$ & $\begin{array}{l}\text { Verificar a influência do TI no } \\
\text { equilíbrio postural e no risco de } \\
\text { quedas de idosos residentes em } \\
\text { ILPIs, por meio de testes funcionais }\end{array}$ & \begin{tabular}{l}
\multicolumn{2}{c}{$52,7 \%$} \\
Tempo de residência em \\
ILPIs, equilíbrio postural, \\
funções cognitivas.
\end{tabular} & $\begin{array}{l}\text { Repensar a política de saúde } \\
\text { para os idosos } \\
\text { institucionalizados, além de } \\
\text { uma restruturação dos métodos }\end{array}$ \\
\hline
\end{tabular}




\begin{tabular}{|c|c|c|c|}
\hline $\begin{array}{l}\text { de idosos: estudo } \\
\text { transversal }\end{array}$ & $\begin{array}{l}\text { do equilíbrio postural e por } \\
\text { estabilometria estática. }\end{array}$ & & $\begin{array}{l}\text { e das estratégias empregadas no } \\
\text { cuidado em saúde desses } \\
\text { indivíduos. }\end{array}$ \\
\hline $\begin{array}{l}\text { Monitoramento de } \\
\text { episódios de quedas } \\
\text { em Instituição para } \\
\text { Idosos }\end{array}$ & $\begin{array}{l}\text { Determinar a taxa de prevalência, } \\
\text { incidência e características dos } \\
\text { episódios de queda em idosos } \\
\text { residentes de uma instituição de } \\
\text { longa permanência. }\end{array}$ & $\begin{array}{l}40,9 \% \\
\text { Ser do sexo feminino, perda } \\
\text { de massa óssea a partir dos } 40 \\
\text { anos. }\end{array}$ & $\begin{array}{l}\text { Criação de um resumo mínimo } \\
\text { de dados que devem ser } \\
\text { registados sempre que um idoso } \\
\text { cai numa IPLI. }\end{array}$ \\
\hline $\begin{array}{l}\text { Coorte de idosos } \\
\text { institucionalizados: } \\
\text { fatores de risco para } \\
\text { queda a partir do } \\
\text { diagnóstico } \\
\text { enfermagem }\end{array}$ & $\begin{array}{l}\text { Conhecer a incidência de quedas } \\
\text { em idosos residentes de instituições } \\
\text { de longa permanência do Distrito } \\
\text { Federal, identificar os aspectos que } \\
\text { envolvem as quedas, quanto aos } \\
\text { fatores de risco, a partir da } \\
\text { aplicação de escalas e da } \\
\text { Taxonomia II da NANDA-I e } \\
\text { definir o nível de acurácia com sua } \\
\text { sensibilidade e especificidade para } \\
\text { aplicação na prática clínica do } \\
\text { enfermeiro }\end{array}$ & $\begin{array}{l}41 \% \\
\text { Mobilidade } \\
\text { prejudicada, } \\
\text { comprometimento } \\
\text { cognição, comprometimento } \\
\text { do equilíbrio, presença de } \\
\text { marcha, problemas nos pés, } \\
\text { sequelas do AVE, } \\
\text { polipatologia, histórico de } \\
\text { queda. }\end{array}$ & $\begin{array}{l}\text { Melhor avaliação da marcha do } \\
\text { idoso, exercícios de } \\
\text { fortalecimento muscular ou } \\
\text { auxílio locomoção, estímulo a } \\
\text { uso de calçados fechados e } \\
\text { confortáveis adaptados aos } \\
\text { problemas nos pés, qualificação } \\
\text { da prestação do cuidado das } \\
\text { equipes dentro das instituições } \\
\text { de longa permanência. }\end{array}$ \\
\hline $\begin{array}{l}\text { Use of fall risk } \\
\text { increasing drugs in } \\
\text { residents of retirement } \\
\text { villages: A pilot study } \\
\text { of long term care and } \\
\text { retirement home } \\
\text { residents in Ontario, } \\
\text { Canada }\end{array}$ & $\begin{array}{l}\text { Descrever os padrões atuais de uso } \\
\text { de FRID em residentes de LTC e } \\
\text { RH que sofreram uma ou mais } \\
\text { quedas durante um período de } 1 \text { ano } \\
(2009-2010) \text { e (2) explorar as } \\
\text { práticas pós-queda atuais como eles } \\
\text { se relacionam ao uso contínuo de } \\
\text { FRIDs. }\end{array}$ & $\begin{array}{l}\text { Sem prevalência } \\
\text { Polifarmácia, quedas } \\
\text { anteriores, demência, } \\
\text { idade avançada, deficiências } \\
\text { sensoriais, uso de dispositivos } \\
\text { ambulatoriais assistivos e } \\
\text { uma alta prevalência de lesões } \\
\text { pós-queda. }\end{array}$ & - \\
\hline $\begin{array}{l}\text { Quedas } \\
\text { Instituições para } \\
\text { idosos: caracterização } \\
\text { dos episódios de } \\
\text { quedas e fatores de } \\
\text { risco associados }\end{array}$ & $\begin{array}{l}\text { Determinar a prevalência de quedas } \\
\text { em idosos institucionalizados; } \\
\text { Caracterizar a queda quanto ao } \\
\text { local, horário, lesões resultantes, } \\
\text { vigilância do idoso, atividade que } \\
\text { estava sendo executada no } \\
\text { momento da queda; Relacionar a } \\
\text { ocorrência de queda com o risco de } \\
\text { queda, diagnósticos médicos, } \\
\text { número de medicamentos que o } \\
\text { idoso faz uso, tipo de medicamento, } \\
\text { grau de dependência, idade e sexo. }\end{array}$ & $\begin{array}{l}37,5 \% \\
\text { Transferências e a marcha, } \\
\text { "escorregar" e "tropeçar". }\end{array}$ & $\begin{array}{l}\text { Perceber como é feito o } \\
\text { seguimento do idoso que sofre } \\
\text { uma queda para evitar a } \\
\text { segunda queda e prevenir o } \\
\text { medo e a perda de } \\
\text { funcionalidade. Além disso, } \\
\text { estudar a organização dos } \\
\text { cuidados nos diferentes turnos e } \\
\text { o dimensionamento de pessoal. }\end{array}$ \\
\hline $\begin{array}{l}\text { Influence of cognitive } \\
\text { impairment on fall } \\
\text { risk among elderly } \\
\text { nursing } \\
\text { residents }\end{array}$ & $\begin{array}{l}\text { Identificar potenciais fatores de } \\
\text { risco de queda, dependendo da } \\
\text { gravidade do prejuízo cognitivo em } \\
\text { residentes de asilos. }\end{array}$ & $\begin{array}{l}\text { Sem prevalência } \\
\text { Humor e comportamento, } \\
\text { motores e funcionais, } \\
\text { neuropsicológicos. }\end{array}$ & - \\
\hline $\begin{array}{l}\text { Quedas em idosos } \\
\text { institucionalizados: } \\
\text { riscos, consequências } \\
\text { e antecedentes }\end{array}$ & $\begin{array}{l}\text { Analisar a ocorrência de quedas em } \\
\text { idosos institucionalizados quanto } \\
\text { aos riscos, consequências e } \\
\text { antecedentes. }\end{array}$ & $\begin{array}{l}\quad 66,7 \% \\
\text { Idade, } \quad \text { analfabetismo, } \\
\text { hipertensão e diversidade da } \\
\text { superfície do solo. }\end{array}$ & $\begin{array}{l}\text { Ajustar altura da cama, uso de } \\
\text { meios antiderrapantes, } \\
\text { iluminação adequada, tapetes } \\
\text { fixos no solo e protetores de } \\
\text { quadril } \\
\text { para reduzir tais riscos. }\end{array}$ \\
\hline $\begin{array}{l}\text { Associação entre } \\
\text { número de quedas e } \\
\text { força muscular de } \\
\text { idosos residentes em } \\
\text { instituições de longa } \\
\text { permanência }\end{array}$ & $\begin{array}{l}\text { Verificar a associação da força } \\
\text { muscular com o risco de quedas de } \\
\text { idosos residentes em ILPIs, } \\
\text { praticantes e não praticantes de } \\
\text { exercício físico. Acredita-se que a } \\
\text { inserção de programas de exercícios } \\
\text { físicos nestes locais } \\
\text { possam ser determinantes para } \\
\text { atenuar as respostas no número de } \\
\text { quedas. }\end{array}$ & $\begin{array}{l}43,3 \% \\
\text { Ser do sexo feminino, idade } \\
\text { avançada, } \\
\text { presença de doenças crônicas, } \\
\text { elevado de uso do } \\
\text { medicamentos, } \\
\text { consequentemente, a presença } \\
\text { da polifarmácia e fraqueza } \\
\text { muscular. }\end{array}$ & $\begin{array}{l}\text { Medidas preventivas e } \\
\text { estratégias orientadas e } \\
\text { supervisionadas por meio da } \\
\text { prática regular de exercícios } \\
\text { físicos, a fim de minimizar a } \\
\text { perda da força muscular } \\
\text { relacionada com o } \\
\text { envelhecimento, para contribuir } \\
\text { na melhora da capacidade } \\
\text { funcional e, na redução do risco } \\
\text { de quedas. }\end{array}$ \\
\hline $\begin{array}{l}\text { Análise dos fatores de } \\
\text { risco para queda em }\end{array}$ & $\begin{array}{l}\text { Identificar o perfil demográfico, } \\
\text { clínico, o contexto de risco e da }\end{array}$ & $27,5 \%$ & $\begin{array}{l}\text { Implementação de protocolos } \\
\text { assistenciais de prevenção de }\end{array}$ \\
\hline
\end{tabular}




\begin{tabular}{|c|c|c|c|}
\hline $\begin{array}{l}\text { idosos } \\
\text { institucionalizados }\end{array}$ & $\begin{array}{l}\text { ocorrência de queda em idosos } \\
\text { institucionalizados; analisar a } \\
\text { associação da classificação de risco } \\
\text { de cair de Morse Fall Scale na } \\
\text { versão brasileira (MFS-B) e a } \\
\text { ocorrência de quedas em idosos } \\
\text { institucionalizados. }\end{array}$ & $\begin{array}{l}\text { Déficit auditivo; Calçados } \\
\text { inadequados; Força diminuída } \\
\text { das mãos. }\end{array}$ & $\begin{array}{l}\text { queda com enfoque } \\
\text { multidisciplinar para minimizar } \\
\text { riscos em idosos de Instituição } \\
\text { de longa permanência; Garantir } \\
\text { a segurança do idoso } \\
\text { institucionalizado. }\end{array}$ \\
\hline $\begin{array}{l}\text { Insomnia, } \\
\text { Benzodiazepine Use, } \\
\text { and Falls among } \\
\text { Residents in Long- } \\
\text { term Care Facilities. }\end{array}$ & $\begin{array}{l}\text { Examinar a associação do sono } \\
\text { qualidade e uso de hipnótico com } \\
\text { risco de quedas, usando um estudo } \\
\text { de coorte prospectivo em } \\
\text { instituições residentes, para } \\
\text { fornecer uma base para a concepção } \\
\text { de estratégias eficazes de prevenção } \\
\text { de quedas nesta população. }\end{array}$ & $\begin{array}{l}\qquad 21.8 \% \\
\text { Insônia e uso de } \\
\text { benzodiazepínicos. }\end{array}$ & $\begin{array}{l}\text { Adotar abordagens não } \\
\text { farmacológicas para melhorar o } \\
\text { sono; } \\
\text { Usar hipinóticos mais seguros; } \\
\text { fortalecer e supervisionar o uso } \\
\text { de benzodiazepinicos para a } \\
\text { prevenção de quedas. }\end{array}$ \\
\hline $\begin{array}{l}\text { Epidemiological } \\
\text { characteristics and } \\
\text { factors influencing } \\
\text { falls among elderly } \\
\text { adults in long-term } \\
\text { care facilities in } \\
\text { Xiamen, China. }\end{array}$ & $\begin{array}{l}\text { Investigar as características } \\
\text { epidemiológicas e identificar os } \\
\text { fatores que influenciam as quedas } \\
\text { em residentes de LTC. }\end{array}$ & $\begin{array}{l}31,7 \% \\
\text { Atividade de vida diária } \\
\text { (AVD); Equilíbrio e marcha; } \\
\text { Condições médicas; Estado } \\
\text { cognitivo, ambiente de vida; } \\
\text { Pés, calçados e perda } \\
\text { sensorial. }\end{array}$ & 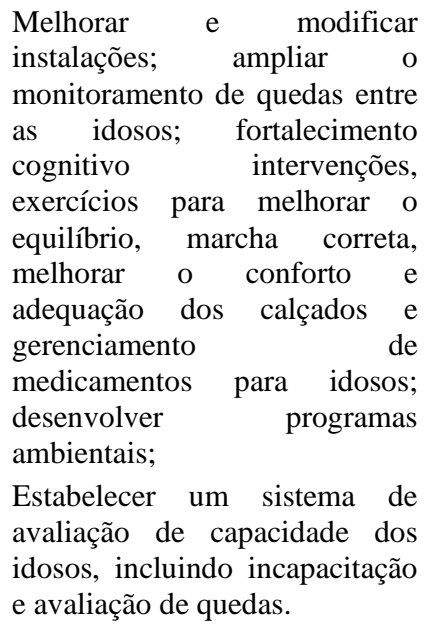 \\
\hline $\begin{array}{l}\text { Recurrent falls and } \\
\text { risk factors among } \\
\text { institutionalized older } \\
\text { people. }\end{array}$ & $\begin{array}{l}\text { Determinar a incidência e os fatores } \\
\text { de risco relacionados a quedas } \\
\text { recorrentes em } \\
\text { institucionalizados }\end{array}$ & \begin{tabular}{l}
\multicolumn{3}{c}{$56,4 \%$} \\
Incontinência \\
declínio de mobilidária; \\
fadiga muscular; usos de \\
betabloqueadores ajustado \\
pelo uso de medicamento \\
antitrombótico; \\
ambientais.
\end{tabular} & $\begin{array}{l}\text { Maior vigilância aos idosos que } \\
\text { já sofreram queda; Criação de } \\
\text { programa de educação } \\
\text { continuada para profissionais de } \\
\text { saúde e cuidadores; Ofertar } \\
\text { programa de apoio aos idosos } \\
\text { que já caíram; Instituir medida } \\
\text { para prevenir fadiga, como } \\
\text { atividades multiprofissionais } \\
\text { que envolvam terapias } \\
\text { psicológicas }\end{array}$ \\
\hline $\begin{array}{l}\text { Correlation between } \\
\text { functional } \\
\text { independence and risk } \\
\text { of falls in older adults } \\
\text { at three long-term } \\
\text { care facilities }\end{array}$ & $\begin{array}{l}\text { Avaliar de que modo a } \\
\text { independência funcional de um } \\
\text { grupo de idosos institucionalizados } \\
\text { se relaciona com seus riscos de } \\
\text { quedas. }\end{array}$ & $\begin{array}{l}45,8 \% \\
\text { Hipertensão arterial sistêmica, } \\
\text { visão comprometida, } \\
\text { luminosidade ambiental e } \\
\text { infraestrutura inadequada. }\end{array}$ & $\begin{array}{l}\text { Planejamento de cuidados } \\
\text { individualizados; } \\
\text { monitoramento na ILP em } \\
\text { relação aos idosos que já } \\
\text { sofreram queda; Adequação do } \\
\text { ambiente de modo a torná-lo } \\
\text { seguro; Educação continuada } \\
\text { para profissionais de saúde e } \\
\text { cuidadores. }\end{array}$ \\
\hline
\end{tabular}

Fonte: Autores (2020).

\section{Discussão}

De acordo com os dados levantados a partir dos artigos selecionados, os fatores associados ao risco de quedas em idosos residentes em Instituição de Longa Permanência e as medidas para prevenção desse risco serão apresentados em duas categorias descritas a seguir. 


\subsection{Fatores associados ao risco de quedas em idosos residentes em Instituição de Longa Permanência}

As quedas são problemas comuns vivenciados na população idosa. No Brasil, cerca de $29 \%$ dos idosos caem ao menos uma vez ao ano e $13 \%$ caem duas vezes ou mais de forma habitual (Ferreira \& Yoshitome, 2010). Neste estudo, a prevalência de quedas em idosos residentes em instituição de longa permanência variou de $21,8 \%$ a $70 \%$. A menor prevalência apresentou como fator de risco para quedas em ILPI a insônia e uso de benzodiazepínicos (Jiang et al., 2019). E a maior prevalência apontou como fatores associados a doença de Alzheimer, tempo de institucionalização, déficit no equilíbrio, dificuldade na marcha, perda de força progressiva, idade mais avançada igual ou superior a 80 anos e sexo feminino (Ferreira et al., 2013).

Ademais, destacaram-se também no estudo como principais fatores associados ao risco de quedas em ILPI: demência, visão comprometida, uso de medicamentos, redução na capacidade da realização da vida diária, tontura, hipertensão, incontinência urinária, sintomas comportamentais, calçados inadequados e infraestrutura inadequada.

Zang et al., (2019) referiu-se que as alterações fisiológicas decorrentes do processo do envelhecimento podem afetar fatores como: distúrbios musculoesqueléticos, instabilidade da marcha, acuidade visual, perda da audição e lesões nos membros inferiores, que podem levam a um considerável índice de risco de quedas.

Dentre as doenças encontradas com fator de risco para quedas destaca-se a hipertensão, pois para o controle do nível da pressão arterial faz-se necessário o uso de anti-hipertensivos que podem causar hipotensão postural e resultar em quedas. Observa-se que parâmetros relacionados a doenças cardiovasculares e o uso de medicamentos também são fatores importantes para risco de quedas em idosos (Araújo Neto et al., 2017).

Estudos realizados no Canadá (Rojas-Fernandez et al., 2015) e Espanha (Seijo-Martinez et al., 2015) são semelhantes aos achados antecedentes, uma vez que observaram que os medicamentos estão associados a um risco aumentado de queda, principalmente os medicamentos psicotrópicos e hipertensivos. Além disso, perceberam também que o uso de vários medicamentos em pessoas idosas é comum, obtendo um consumo de cinco medicamentos ou mais por dia. Esse aspecto é considerado como polifarmácia e devido a sua alta taxa de uso e potencial para sua modificação, assim como possíveis interações medicamentosas que geram efeitos colaterais, são fatores que levam os idosos a sofrerem quedas.

Segundo Álvares et al. (2010) observaram que o sexo feminino representa a maior parte da população de idosos, isso caracteriza-se devido as mulheres idosas viverem mais do que os homens. Além disso, em seu estudo os autores apontaram que as mulheres sofreram cerca de duas vezes mais quedas que os homens. No entanto, Ferreira e Yoshitome (2010) abordaram que não se tem uma explicação definida sobre este fato, no entanto, acredita-se que a maior mobilidade e a menor quantidade de massa magra e a força muscular são menores em idosas, proporcionando assim maior exposição ao risco de queda. Baixinho e Dixe (2014) corroboram com os demais autores e contribuem referindo-se que associação entre massa magra e quedas se dá por causa da redução do estrógeno que favorece a deterioração do estado funcional e as doenças crônicas aumentando assim o risco de quedas.

No estudo de Ferreira e Yoshitome (2010) verificou-se ainda que a maioria dos idosos que caíram é parcialmente dependente. Observou-se que a redução na capacidade de realização das atividades de vida diária é um relevante fator de risco, uma vez que o idoso com declínio funcional apresenta risco aumentado para quedas em decorrência da baixa autoconfiança para realizar as atividades da vida diária, o que compromete ainda mais sua capacidade funcional. Nesse sentido, Del Duca, Antes e Hallal (2013) são de acordo com o achado anterior e abordam que os idosos institucionalizados, com incapacidade funcional em até cinco atividades apresentaram alta probabilidade de sofrerem quedas.

Zang et al., (2019) discutem que as principais causas de quedas incluem causas internas e externas, referindo-se que as causas externas estão ligadas com o ambiente em que residem e com o uso inadequado de calçados. Rosa et al. (2019) confirmam o achado e retratam que o desequilíbrio e o escorregão são outros fatores que podem causar a queda. O 
desequilíbrio pode estar associado a fatores do próprio envelhecimento, bem como o escorregão está associado a fatores ambientais e pessoais. Para mais, o déficit de equilíbrio está presente em indivíduos que já caíram, pois apresentam maior oscilação anteroposterior em posição ereta comparado àqueles que nunca caíram (Paula et al., 2020).

Além dos fatores ambientais referidos pelos autores anteriores é importante frisar a relação desses com a incontinência urinária, uma vez que tal fator contribui para o número de vezes que o idoso vai ao banheiro, podendo neste percurso tropeçar e cair, principalmente à noite, quando a luminosidade é mais precária e a visão fica comprometida (Ferreira et al., 2019).

De um modo geral, todos os artigos trouxeram fatores associados aos possíveis comprometimentos nas condições de saúde dos idosos em relação aos riscos e comprovaram que tais eventos são umas das principais causas de incapacidade funcional, podendo gerar consequências para essa população.

\subsection{Mecanismos de prevenção desse evento nos idosos residentes nessas instituições}

Quanto aos mecanismo de prevenção destacaram-se: ampliar monitoramento e o fortalecimento daqueles que sofrem com comprometimento cognitivo e quedas, realizar diagnóstico precoce de comprometimentos visuais e ou correção desses, uso de hipnótico mais seguro, fortalecimento e supervisão de benzodiazepínicos, implementar medidas de segurança nas instalações como: ajuste na altura das camas, uso de tapetes fixos no solo e protetor de quadril para evitar lesões, implementar exercício para melhorar a marcha correta, reabilitação da força muscular, equilíbrio e capacidade funcional, redução da polifarmácia, educação para o autocuidado e aumento da supervisão de enfermagem nos períodos e locais de maior incidência de quedas.

Devido a prevalência de queda significativa em idosos residentes em Instituições do Longa Permanência, Ferreira e Yoshitome (2010) sugeriram uma avaliação constante dos profissionais de saúde sobre os idosos que caem e aqueles que não caem, no sentido de identificar os fatores intrínsecos e extrínsecos para implementar estratégias de prevenção que reabilite a força muscular, equilíbrio e capacidade funcional do idoso, redução da polifarmácia, educação para o autocuidado e supervisão da enfermagem em locais com maior incidência de queda.

Tais fatores corroboram com estudo realizado por Menezes e Bachion (2012b), o qual acrescenta a importância de realizar programas de exercícios físicos e instituir boletim de quedas com data, hora e local da ocorrência a fim de promover redução de quedas.

Sabe-se que o envelhecimento é caracterizado por um declínio funcional de órgãos e sistemas, sendo influenciado por fatores genéticos e fisiológicos. Dessa forma, repensar em política de saúde para os idosos institucionalizados, além de uma restruturação dos métodos e das estratégias empregadas no cuidado em saúde desses indivíduos (Batista et al., 2014), como também na criação de um resumo mínimo de dados que devem ser registrados sempre que um idoso cair numa IPLI (Baixinho \& Dixe, 2014) são considerados mecanismos de prevenção que diminuem a prevalência de quedas.

Além disso, perceber como é feito o seguimento do idoso que sofre uma queda para evitar a segunda e prevenir o medo, assim também como a perda de funcionalidade, são mecanismos de prevenção apontados por Baixinho e Dixe (2016) em seu estudo. Para mais, os autores sugerem que estudar a organização dos cuidados nos diferentes turnos e o dimensionamento de pessoal, influencia tanto na redução das quedas quanto na melhor prestação de serviços pelos profissionais de saúde.

Estudo de Hasegawa et al. (2010) realizado no Japão, demonstrou que incontinência urinária e sintomas comportamentais são potenciais fatores de risco de quedas recorrentes e prejudiciais, respectivamente, entre os idosos em ambientes de cuidados de longa duração. E apontam o tratamento ou gestão da incontinência urinária como fator contribuinte na prevenção de quedas em idosos que se encontram em instituições de cuidados de longo prazo. 
De antemão, Menezes e Bachion (2012a), ao fazerem associação entre o déficit visual referido pelos idosos e a ocorrência de quedas entre eles, detectaram que entre os déficits visuais corrigidos com órtese, os déficits não corrigidos e sem déficit, os que mais prevaleceram foram justamente os déficits visuais autorrelatos. Com isso os autores orientaram como mecanismos de prevenção, o diagnóstico precoce de comprometimento visual ou correção, visto que o sistema visual é um importante contribuinte para o equilíbrio, fornecendo informações sobre o ambiente, localização, direção e a velocidade de movimento do idoso.

Reis e Jesus (2015) ressaltam que melhorar a avaliação da marcha dos idosos, propor exercícios de fortalecimento muscular, estimular ao uso de calçados fechados/confortáveis e qualificar a prestação do cuidado das equipes dentro das instituições de longa permanência poderão permitir a promoção, prevenção e reabilitação dos idosos institucionalizados, assim como minimizar os riscos de quedas e lesões.

Como também, Tomicki et al., (2017) e Valcarenghi et al., (2014) reforçam a relevância de medidas preventivas e estratégicas, a fim de melhorar a força da perda muscular para contribuir na melhoria da capacidade funcional e do risco de queda. Destaca-se ainda, que segundo os estudos de Del Duca et al. (2013) e Araújo Neto et al., (2017), o ajuste na altura da cama, uso de meios antiderrapantes, iluminação adequada, tapetes fixos no solo e protetores de quadril, ambientes físicos adequados e profissionais capacitados, poderão ser valiosas ferramentas na prevenção ao risco de quedas em ILPI.

Jiang et al., (2019) evidenciaram que tanto a insônia quanto o uso de benzodiazepínicos entre residentes de instituições de longa duração são importantes fatores de risco para quedas. Porém os autores demonstram preocupação quanto as medidas preventivas em relação a esses fatores pelo fato de possuírem poucos estudos focados em abordar o sono e uso de hipnóticos como uma forma de minimizar quedas, visto que são queixas muito comuns em casas de longa duração. Com isso o autor sugere lançar como prática de prevenção em ambientes de longa duração, a adoção de abordagens não farmacológicas para melhorar o sono, usar hipinóticos mais seguros e fortalecer a supervisão de benzodiazepinicos para prevenção das quedas.

Rosa, Cappellari e Urbaneto (2019) buscam como mecanismo de prevenção para tais fatores discutidos no estudo, implementação de protocolos assistenciais de prevenção de queda com enfoque multidisciplinar para minimizar riscos em idosos de Instituição de longa permanência, garantir a segurança do idoso institucionalizado. Ferreira et al., (2019), sugerem também maior vigilância aos idosos que já sofreram queda, criação de programa de educação continuada para profissionais de saúde e cuidadores, além de programa de apoio aos idosos que já caíram.

Nesse sentido, Paula et al., (2020) apontam o planejamento de cuidados individualizados, monitoramento na ILP em relação aos idosos que já sofreram queda, adequação do ambiente de modo a torná-lo seguro e educação continuada para profissionais de saúde e cuidadores como práticas preventivas em relação as quedas. Assim, pode-se observar que tais medidas mostram semelhanças entre si.

Zhang et al., (2019) corroboram com maioria das medidas supracitadas no estudo, quando dizem que para minimizar tais ocorrências é necessário melhorar e modificar instalações, ampliar o monitoramento de quedas entre os idosos, fortalecer a parte cognitiva dos idosos, realizar exercícios para melhorar o equilíbrio, a marcha correta, além de melhorar o conforto e adequação dos calçados, gerenciar medicamentos, desenvolver programas ambientais, assim como estabelecer um sistema de avaliação de capacidade dos idosos, incluindo incapacitação e avaliação de quedas.

\section{Conclusão}

Identificou-se nesta revisão integrativa, artigos que dissertaram sobre fatores associados ao risco de quedas em idosos residentes em Instituição de Longa Permanência, a prevalência e as possíveis prevenções para esse evento. Foi evidenciado tratar-se de temática ainda recente, porém com significativa prevalência em idosos institucionalizados, o que requer urgente adoção de métodos preventivos. 
Dentre os fatores precípuos que incidem diretamente no evento queda nessa população destacou-se: demência, doença de Alzheimer, visão comprometida, uso de medicamentos, tempo de institucionalização, déficit no equilíbrio, dificuldade na marcha, perda de força progressiva, idade mais avançada igual ou superior a 80 anos, sexo feminino, redução na capacidade da realização da vida diária, tontura, hipertensão, incontinência urinária, sintomas comportamentais, calçados inadequados e infraestrutura inadequada.

Dessarte, o risco de queda é considerado uma das principais causas de mortes entre idosos, o que aponta a necessidade de ações preventivas que requerem ampliação do monitoramento, do fortalecimento cognitivo, promoção do diagnóstico precoce de comprometimentos visuais e a correção desses, a implementação de medidas de segurança como a utilização de tapetes fixos, ajustes na altura das camas, o incentivo a prática de exercício físico para melhora da marcha, reabilitação da força muscular e capacidade funcional, redução da polifarmácia, reeducação para o autocuidado e autonomia e o aprimoramento da supervisão da enfermagem nos locais de maior incidência de quedas.

Tais intervenções mostram o enfrentamento da problemática e apontam o enfermeiro como integrante da equipe multiprofissional diretamente ligado ao cuidado ao idoso, para a promoção de discussões e avanços na assistência a esses indivíduos enquanto institucionalizados a fim de possibilitar o direcionamento de outros profissionais e o progresso científico multidisciplinar.

A incipiente produção de estudos experimentais sobre a temática apontou uma importante lacuna e representou uma limitação, no sentido de possibilitar comparação de intervenções de enfermagem para enfrentamento do problema. A articulação multiprofissional e intersetorial pode favorecer o engajamento de toda sociedade em busca de soluções efetivas para a redução do número de quedas em decorrência do processo de envelhecimento entre os idosos institucionalizados.

\section{Referências}

Álvares, L. M., Lima, R. D. C., \& Silva, R. A. D. (2010). Ocorrência de quedas em idosos residentes em instituições de longa permanência em Pelotas, Rio Grande do Sul, Brasil. Cadernos de Saúde Pública, 26, 31-40.

Araújo Neto, A. H. D., Patrício, A. C. F. D. A., Ferreira, M. A. M., Rodrigues, B. F. L., Santos, T. D. D., Rodrigues, T. D. D. B., \& Silva, R. A. R. D. (2017). Quedas em idosos institucionalizados: riscos, consequências e antecedentes. Revista brasileira de enfermagem, 70(4), $719-725$.

Baixinho, C. L., \& Dixe, M. dos A. (2014). Monitoramento de episódios de quedas em Instituição para Idosos. Revista Eletrônica De Enfermagem, 16(1), 2834.

Baixinho, C. R. S. L., \& Dixe, M. D. A. C. R. (2015). Quedas em Instituições para idosos: caracterização dos episódios de quedas e fatores de risco associados. Revista Eletrônica de Enfermagem, 17(4).

Batista, W. O., Alves Junior, E. D., Porto, F., Pereira, F. D., Santana, R. F., \& Gurgel. J. L. (2014). Influência do tempo de institucionalização no equilíbrio postural e no risco de quedas de idosos: estudo transversal. Rev. Latino-Am. Enfermagem, 22(4), 645-653.

Carvalho, V. L. D. (2014). Perfil das instituições de longa permanência para idosos situadas em uma capital do Nordeste. Cadernos Saúde Coletiva, 22(2), 184-191.

Corassa, R. B., Falci, D. M., Gontijo, C. F., Machado, G. V. C., \& Alves, P. A. B. (2017). Evolução da mortalidade por causas externas em Diamantina (MG), 2001 a 2012. Cadernos Saúde Coletiva, 25(3), 302-314.

Del Duca, G. F., Antes, D. L., \& Hallal, P. C. (2013). Quedas e fraturas entre residentes de instituições de longa permanência para idosos. Revista Brasileira de Epidemiologia, 16, 68-76.

Fagundes, K. V. D. L., Esteves, M. R., Ribeiro, J. H. D. M., Siepierski, C. T., Silva, J. V. D., \& Mendes, M. A. (2017). Instituições de longa permanência como alternativa no acolhimento das pessoas idosas. Revista de Salud Pública, 19, 210-214.

Ferreira, L. L., Sanches, G. G. A., Marcondes, L. P., \& Saad, P. C. B. (2013). Risco de queda em idosos institucionalizados com doença de Alzheimer. Revista Kairós: Gerontologia, 16(3), 95-105.

Ferreira, L. M. D. B. M., Ribeiro, K. M. O. B. D. F., Jerez-Roig, J., Araújo, J. R. T., \& Lima, K. C. D. (2019). Recurrent falls and risk factors among institutionalized older people. Ciencia \& saude coletiva, 24, 67-75.

Ferreira, D. C. D. O., \& Yoshitome, A. Y. (2010). Prevalência e caraterísticas das quedas de idosos institucionalizados. Revista Brasileira de Enfermagem, 63(6), 991-997. 
Freitas, V. P., do Carmo, N. A., Raimundo, B. D. C. A., Santos, A. O., de Araújo, C. M., \& dos Reis, L. A. (2017). Avaliação do risco de quedas dos idosos residentes em instituição de longa permanência no Brasil: uma revisão integrativa. Revista Brasileira de Ciências do Envelhecimento Humano, 14(3).

Galvão, C. M., Mendes, K. D. S., \& Silveira, R. C. C. P. (2010). Revisão integrativa: método de revisão para sintetizar as evidências disponíveis na literatura. (4a ed.), Iátria, 102-123.

Gomes, E. C. C., Marques, A. P. D. O., Leal, M. C. C., \& Barros, B. P. D. (2014). Fatores associados ao risco de quedas em idosos institucionalizados: uma revisão integrativa. Ciência \& Saúde Coletiva, 19, 3543-3551.

Hasegawa, J., Kuzuya, M., \& Iguchi, A. (2010). Urinary incontinence and behavioral symptoms are independent risk factors for recurrent and injurious falls, respectively, among residents in long-term care facilities. Archives of gerontology and geriatrics, 50(1), 77-81.

Instituto Brasileiro de Geografia e Estatística (IBGE). (2018). Projeção da população: número de habitantes do país deve parar de crescer em 2047. Dados do Censo. <https://agenciadenoticias.ibge.gov.br/agencia-sala-de-imprensa/2013-agencia-de-noticias/releases/21837-projecao-da-populacao-2018-numero-dehabitantes-do-pais-deve-parar-de-crescer-em-2047>.

Jiang, Y., Xia, Q., Wang, J., Zhou, P., Jiang, S., Diwan, V. K., \& Xu, B. (2019). Insomnia, benzodiazepine use, and falls among residents in long-term care facilities. International journal of environmental research and public health, 16(23), 4623.

Karino, M. E., \& Felli, V. E. A. (2012). Enfermagem baseada em evidências: avanços e inovações em revisões sistemáticas. Ciência, Cuidado e Saúde, 11, 011-015.

Linder, L. R., Rocha, I. C., Katagiri, S., \& da Silva, P. N. (2020). Quedas em idosos institucionalizados: ocorrência e consequências/Falls in institutionalized elderly: occurrence and consequences. Journal of Nursing and Health, 10(1).

Marziale, MHP (2015). Instrumento de coleta de dados, revisão integrativa. Recuperado de: http://gruposdepesquisa.eerp.usp.br/sites/redenso/wpcontent/uploads/ sites/9/2016/04/Instrumiento-revision-de-la-litetaruraRedENSO-2017.pdf

Menezes, R. L. D., \& Bachion, M. M. (2012a). Ocorrência de quedas e seu contexto num seguimento de dois anos em idosos institucionalizados. Rev. Eletr. Enf., 14 (3), 550-558.

Menezes, R. L. D., \& Bachion, M. M. (2012b). Condições visuais autorrelatadas e quedas em idosos institucionalizados. Revista Brasileira de Oftalmologia, 71(1), 23-27.

Moher, D., Liberati, A., Tetzlaff, J., Altman, D. G., \& Prisma Group. (2009). Itens de relatório preferidos para revisões sistemáticas e meta-análises: a declaração PRISMA. Medicamento PLoS, 6 (7), e1000097.

Organização Mundial da Saúde (OMS). (2010). Relatório global da OMS sobre prevenção de quedas na velhice. http://www.saude.sp.gov.br/resources/ccd/publicacoes/publicacoes-ccd/saude-e-populacao/m anual_oms_-_site.pdf.

Paula, J. G. F. D., Gonçalves, L. H. T., Nogueira, L. M. V., \& Delage, P. E. G. A. (2020). Correlation between functional independence and risk of falls in older adults at three long-term care facilities. Revista da Escola de Enfermagem da USP, 54, e3601.

Reis, K. M. C., \& Jesus, C. A. C. (2015) Coorte de idosos institucionalizados: fatores de risco para queda a partir do diagnóstico de enfermagem. Rev. LatinoAm. Enfermagem, 23 (6), 1130-1138.

Rojas-Fernandez, C., Dadfar, F., Wong, A., \& Brown, S. G. (2015). Use of fall risk increasing drugs in residents of retirement villages: a pilot study of long term care and retirement home residents in Ontario, Canada. BMC research notes, $8(1), 1-9$.

Rosa, V. P. P., Cappellari, F. C. B. D., \& Urbanetto, J. S. (2019). Análise dos fatores de risco para queda em idosos institucionalizados. Revista Brasileira de Geriatria e Gerontologia, 22(1), e180138.

Seijo-Martinez, M., Cancela, J. M., Ayán, C., Varela, S., \& Vila, H. (2016). Influence of cognitive impairment on fall risk among elderly nursing home residents. International psychogeriatrics, 28(12), 1975-1987.

Silva, K. M., Vicente, F. R., \& Santos, S. M. A. D. (2014). Consulta de enfermagem ao idoso na atenção primária à saúde: revisão integrativa da literatura. Revista Brasileira de Geriatria e Gerontologia, 17(3), 681-687.

Tomicki, C., Cecchin, L., Zanini, S. C. C., Benedetti, T. R. B., Leguisamo, C. P., \& Portella, M. R. (2017). Associação entre número de quedas e força muscular de idosos residentes em instituições de longa permanência. Revista Kairós: Gerontologia, 20(2), 101-116.

United Nations. (2017). World population aging 2017: highlights: United Nations. http://www.un.org/en/development/desa/population/p ublications/pdf/ageing/WPA2017_Highlights.pdf.

Valcarenghi, R. V., Santos, S. S. C., de Almeida, H. K. S., Barlem, E. L. D., Gomes, G. C., \& Silva, B. T. D. (2014). Ações institucionais alicerçadas em diagnósticos de enfermagem para prevenção de quedas em idosos. Rev Rene, 15 (2), 224-32.

Zhang, L., Zeng, Y., Weng, C., Yan, J., \& Fang, Y. (2019). Epidemiological characteristics and factors influencing falls among elderly adults in long-term care facilities in Xiamen, China. Medicine, 98(8). 